\title{
Itinerarios teóricos sobre burocracia y política: de la tensión weberiana a las soluciones de compromiso
}

GRACIELA INDA*

Artículo recibido: 17 de diciembre de 2019

Artículo aceptado: 12 de agosto de 2020

Doi: https://doi.org/10.12804/revistas.urosario.edu.co/desafios/a.8553

Para citar este artículo: Inda, G. (2021). Itinerarios teóricos sobre burocracia y política: de la tensión weberiana a las soluciones de compromiso. Desafios, 33(2), 1-33.

https://doi.org/10.12804/revistas.urosario.edu.co/desafios/a.8553

\section{Resumen}

Con la ambición de aportar a la construcción de una cartografía que localice las cambiantes hegemonías discursivas en el campo académico, este trabajo tiene por objetivo identificar las formas más relevantes que adopta el vínculo entre burocracia estataly politica en el espacio abierto por la clásica intervención de Weber. En concreto, tras analizar la fórmula weberiana que alude a una tensión complementaria entre cuadro administrativo y práctica politica, reconocemos, sin pretensión de exhaustividad, cinco estrategias o direcciones teóricas diferenciadas: la que concibe la burocracia como un espacio atravesado por tensiones políticas internas que condiciona su rol respecto de la politica; la que define la burocracia como una fuerza que interviene siguiendo intereses propios; la que ve en la tecnocracia una nueva clase o élite políticamente

\footnotetext{
* Instituto Multidisciplinario de Estudios Sociales Contemporáneos (IMESC). Nodo Mendoza del Instituto de Estudios Históricos, Económicos, Sociales e Internacionales (IDEHESI). Comisión Nacional de Investigaciones Científicas y Técnicas (Conicet) - Universidad Nacional de Cuyo (UNCuyo). Correo electrónico: gracielainda@hotmail.com. ORCID: https://orcid.org/0000-0003-2139-7310
} 


\title{
2 / GRACIELA INDA
}

dominante; la que sostiene que políticos y burócratas son actores interdependientes; la que delimita a los burócratas como gestores estratégicos con capacidades politicas. Palabras clave: Weber; enfoques teóricos; burocracia; politica; Estado; autonomia; interdependencia.

\section{Theoretical Itineraries on Bureaucracy and Politics: From Weberian Tension to Compromise Solutions}

\begin{abstract}
This work aims to identify the most relevant approaches that the link between state bureaucracy and politics can take within the space opened by Weber's classic intervention. I seek to contribute to the construction of a cartography that locates the changing discursive hegemonies in the academic field. First, I analyze the Weberian formulation that alludes to a complementary tension between administrative cadre and political practice. Afterwards, I identify six distinct, but non-exhaustive, theoretical strategies or directions: one that conceives of bureaucracy as a space crossed by internal political tensions that condition its role in relation to politics; one that defines bureaucracy as a force that intervenes guided by its own interests; one which sees in technocracy a new politically dominant class or elite; one that maintains that politicians and bureaucrats are interdependent actors; and a perspective that delimits bureaucrats as strategic managers with political capabilities.
\end{abstract}

Keywords: Weber; theoretical approaches; bureaucracy; State; autonomy; interdependence.

\section{Itinerários teóricos sobre burocracia e política: da tensão weberiana às soluções de compromisso}

\begin{abstract}
Resumo
Com a ambição de aportar à construção de uma cartografia que localize as variáveis hegemonias discursivas no campo acadêmico, este trabalho tem por objetivo
\end{abstract}


identificar as formas mais relevantes que adota o vínculo entre burocracia estatal e política no espaço aberto pela clássica intervenção do Weber. Especificamente, após analisar a fórmula weberiana que alude a uma tensão complementária entre quadro administrativo e prática política, reconbecemos, sem pretensão de exaustividade, seis estratégias ou direçoes teóricas diferenciadas: a que concebe a burocracia como um espaço atravessado por tensões politicas internas que condiciona seu papel respeito àpolítica; a que define a burocracia como uma força que intervém seguindo interesses próprios; a que vê na tecnocracia uma nova classe ou elite politicamente dominante; a que sustenta que politicos e burocratas são atores interdependentes; a que delimita aos burocratas como gestores estratégicos com capacidades politicas.

Palavras-chave: Weber; enfoques teóricos; burocracia; politica; Estado; autonomia; interdependência.

\section{Introducción}

Presente en los estudios académicos sobre la burocracia desde fines del siglo XIX, el problema de la relación entre política y administración estatal motiva en su decurso, afirman Brown y Erie (1984), una marcada ambivalencia: en un extremo, la burocracia aparece como una herramienta eficiente y racional para el logro de objetivos políticos; en el otro, es considerada un leviatán incontrolable. De Sheinbaum (1980), en un tono similar, sostiene que las teorías sobre la burocracia estatal van desde considerarla amas o fuerzas dominantes hasta verlas como esclavas de los intereses políticos. Si bien adopta nuevas etiquetas, la vieja dicotomía entre política y administración, subraya Oszlak (1980), mantiene su vigencia en tanto presupone dos modelos diferentes de hacer política, el de la racionalidad técnica, que pretende aplicar criterios universales de elección racional; y el de la racionalidad política, que se basa en el conflicto, la negociación y el compromiso. ${ }^{1}$

Román Masedo (1997), en cambio, encuentra que las investigaciones que desde los setenta plantean una interdependencia entre políticos y funcionarios tienen como efecto una crisis perdurable del paradigma

\footnotetext{
1 El autor desarrolla un marco analítico propio que pretende superar esta polarización y tiene por objeto estudiar las dinámicas intraburocráticas y los estilos de gestión estatal bajo distintos regímenes políticos.
} 


\section{4 / GRACIELA INDA}

weberiano que distingue entre acción política y administración. De manera análoga se expresa Zabludowski (2000) cuando alega que las revisiones que ha sufrido el modelo clásico de la separación entre política y administración estatal han tenido como efecto un cuestionamiento de la supuesta neutralidad política de la burocracia para resaltar su papel en la planeación y ejecución de políticas públicas. Machiavelli y Proulx (2006) apuestan nuevamente por reconocer en el campo académico dos grandes tendencias. Una que concibe la política y la administración como esferas claramente separadas, la primera a cargo de la concepción y elaboración de las políticas, y la segunda de su ejecución. Otra que subraya que la frontera entre política y administración no es tan nítida y que se trata de un proceso en el que los dos actores comparten el poder según diferentes modos.

Con la ambición de aportar a una cartografía más completa que localice las cambiantes hegemonías discursivas en el campo académico, este trabajo tiene por objetivo identificar (aun allí donde no son explícitos) qué itinerarios teóricos suscita la fórmula weberiana. Sin ánimo de exhaustividad, imposible en un terreno tan poblado y diverso, proponemos un recorrido acotado pero ilustrativo de las principales formas que adopta el vínculo entre burocracia estatal y política en el espacio abierto por la intervención weberiana.

Ese punto de partida no resulta de una elección arbitraria. La caracterización presentada por Weber (1922/1969, pp. 173-179, 716-752) sobre la administración del Estado moderno como forma de dominación política formalmente sometida a un derecho racional conformado por un conjunto de reglas abstractas y estatuido intencionalmente con la pretensión de ser respetado por todos (incluso por el soberano) sigue siendo el punto de partida ineludible de los abordajes académicos sobre el tema. No obstante, como bien señala Chazel (2000), si bien resulta a primera vista familiar, la propuesta weberiana no siempre es correctamente aprehendida. En efecto, no es extraño encontrar autores que homologan la posición teórico-política de Weber con la de Wilson (1887), la cual promueve una separación tajante entre las cuestiones administrativas y las políticas como modo de asegurar a 
la burocracia profesional su independencia frente al 'tráfico de influencias' del sistema democrático. Primera estación entonces, Weber.

\section{Política burguesa y burocracia como binomio en tensión}

Junto a la racionalidad creciente de las reglas y las prácticas jurídicas, los rasgos distintivos del aparato burocrático moderno son, según el conocido planteo weberiano, la existencia de una jerarquía administrativa, la exigencia de formación profesional para la aplicación racional de las reglas formales, la vigencia del principio administrativo de atenerse al expediente (la garantía del documento escrito versus la improvisación), la ausencia de formas de apropiación del cargo por parte de quienes lo ejercen y la separación plena entre el cuadro administrativo y los medios materiales de la administración. Así definida, la burocracia estatal, cuyo poder basado en el saber de la especialidad no hace más que acrecentarse merced al conocimiento cotidiano de los expedientes, tiene, para Weber, un carácter permanente y conforma, en conjunción con el monopolio de la fuerza legítima, la piedra angular del Estado moderno.

Las luchas por el poder político pueden producir cambios en el control del aparato burocrático, pero no su transformación sustancial. En una argumentación bien conocida, relativa a la posibilidad de una revolución socialista, se asegura que la burocracia, creada en las condiciones capitalistas, seguiría en pie porque la necesidad de una administración permanente y calculable la torna irrefrenable en las sociedades de masas (Weber, 1922/1969). Ahora bien, lejos de justificar una rendición de la política a la lógica de la administración, Weber se muestra preocupado por el fenómeno del despotismo burocrático, esto es, por la usurpación de las decisiones políticas por parte de los burócratas, y traza una diferencia que considera sustantiva entre el funcionario y el político.

En oposición a la práctica del funcionario, que inspirada en el sacrifico y la disciplina se orienta a administrar imparcialmente y a 


\section{6 / GRACIELA INDA}

obedecer las órdenes de las jerarquías superiores, la vocación de los hombres políticos, que toman partido y luchan por sus convicciones, se sustenta en el honor y la responsabilidad personal por sus actos. Mientras los burócratas son reclutados según su formación y capacitación profesional, los dirigentes políticos, sobre todo los líderes, se seleccionan en la arena de los partidos y los parlamentos según cualidades personales, como la seguridad interna, la pasión por una causa, la ambición de poder, la fuerza discursiva para movilizar a las masas (Weber, 1919/1983). Ambas figuras mantienen entre sí lo que podríamos llamar un vínculo complementario en tensión permanente. Si a los políticos les corresponde decidir los objetivos, imponerlos en la lucha, convencer a las masas de apoyarlos y aceptar las consecuencias, a los funcionarios les cabe apoyarse en su saber específico y guiarse por cánones de orden técnico una vez que dichos objetivos se han resuelto en la pugna política.

La acción política, aunque decisiva, no puede obviar que la burocracia legal racional, dotada de una capacidad técnica superior a toda organización conocida2 y de una disciplina rigurosa que la torna prácticamente inquebrantable, "[...] procura incrementar esta superioridad del saber profesional por medio del secreto de sus conocimientos e intenciones" (Weber, 1922/1969, p. 744). Pero el desafío vale la pena, puesto que una burocracia desarrollada conforma "[...] un recurso de poder de primera clase para aquel que dispone del aparato burocrático. Pues dadas las mismas probabilidades, la acción racional, metódicamente ordenada y dirigida es superior a toda acción contraria de las masas o a toda acción comunitaria que se le oponga" (Weber, 1922/1969, p. 741).

¿A qué se refiere Weber cuando define la política como acción que puede impedir el burocratismo? A los liderazgos políticos que surgen en el terreno de una clase económicamente fuerte (la burguesía) con

\footnotetext{
2 La precisión, la rapidez, la univocidad, la oficialidad, la continuidad, la uniformidad, la rigurosa subordinación, el ahorro de fricciones y de costas objetivas y personales hacen que funcione, según las famosas palabras de Weber, de la misma manera que una máquina con relación a los métodos no mecánicos de fabricación (1922/1969, pp. 730-731).
} 
conciencia política (Beetham, 1967). Las masas, emergentes de un proceso de igualación social que ha destruido las relaciones tradicionales, se insertan inevitablemente en la arena política, pero lo pueden hacer según formas ordenadas y reguladas, siguiendo canales institucionales, o adoptando formas irracionales y agitadas (Inda, 2012).

Convencido de que la democratización constituye una tendencia tenaz, Weber considera que junto a los mecanismos plebiscitarios debe existir un régimen parlamentario efectivo que actúe como obstáculo para la dominación del populacho (Abellán, 2004). ${ }^{3} \mathrm{El}$ pueblo debe dejarse guiar por una auténtica aristocracia política o por un hombre de confianza, salidos de la lucha parlamentaria y partidista (Weber, 1919/1984). "Sólo la dirección ordenada de las masas por políticos responsables puede poner fin al irregular dominio de la calle y al predominio de los demagogos del momento" (Weber, $1921 / 1972$, p. 482).

Si, por un lado, la importancia del magnetismo carismático de los líderes políticos (cesarismo) en los Estados de masas en los que está vigente el sufragio universal tiene la ventaja de disminuir el peso de la burocratización, por otro lado, introduce el peligro de la emotividad de las masas, expuestas a influencias irracionales. "[...] La mente clara y fría - y una política próspera, y sobre todo, una política democrática próspera - domina en las decisiones responsables: 1) cuanto más pequeño sea el número de los participantes en las deliberaciones, 2) cuanto más claras estén las responsabilidades de cada uno y las de aquellos a quienes ellos dirigen” (Weber, 1918/2003, pp. 360-361).

Con sus peligros, los mecanismos de competencia propios de las democracias plebiscitarias constituyen para Weber el medio más adecuado para la selección y la formación de conductores políticos capaces de imponer su propia dirección a la burocracia (Beetham,

\footnotetext{
3 Anter (2010) considera que Weber tiene más éxito en la formulación del problema que en el planteo de una solución, puesto que el Parlamento llamado a ejercer el control de la máquina burocrática se encuentra a su vez cada vez más sometido a un proceso de burocratización que transforma constantemente el conocimiento público en un saber secreto.
} 
1967; Mommsen, 1981). Como resultado, el ejercicio efectivo del poder se encuentra en manos de una minoría, en parte compuesta por políticos con cualidades carismáticas y en parte por burócratas expertos y consecuentes, en una combinación no carente de tensiones. En un sistema presidencial, por ejemplo, el vértice es ocupado por un líder al que le corresponde dar unidad a la administración a la vez que actuar "[...] como una especie de transformador que habrá de capturar las energías de la nueva legitimidad democrática, reunirlas y servírselas al aparato burocrático" (Breuer, 1996, p. 161). El recelo weberiano ante el desplazamiento del poder político por la práctica disciplinada del aparato administrativo no ha dejado de informar análisis contemporáneos, desde los que se muestran más pesimistas respecto de las posibilidades de controlar políticamente el creciente poder burocrático, que tiende a convertir las decisiones políticas en automatismos reglados (Smith, 1988; Bellido, 2017), hasta los que valorizan, en el contexto de las democracias europeas, el rol central del Parlamento, considerado una institución política representativa de la ciudadanía en la que se produce la deliberación entre puntos de vista opuestos y la toma de decisiones soberanas, contra la hegemonía del aparato burocrático (Palonen \& Rosales, 2015; Ihalainen \& Palonen, 2018).

\section{La política en la burocracia}

Referente crucial de la escuela estructural funcionalista, Merton (1949/1965) adhiere al binomio weberiano al considerar que de forma típica, más allá de algunas excepciones, los técnicos e intelectuales de la burocracia proporcionan la información y la experticia instrumental (sobre medios, alternativas posibles, necesidades por tener en cuenta, etc.) para que sus clientes, los políticos, puedan traducir sus decisiones estratégicas en programas de acción o en políticas específicas. Ahora bien, y aquí reside su célebre aporte, en el logro de esas metas, la organización burocrática presenta limitaciones y tensiones 
que pueden derivar en verdaderas patologías. ${ }^{4}$ La burocracia legal racional requiere un grado extraordinario de conformidad con las normas de acción prescriptas, una disciplina reforzada por sentimientos poderosos que impongan al funcionario la devoción a sus deberes de obediencia. Pero cuando la adhesión a las reglas, concebida como un medio, se transforma en un fin en sí mismo e impide la adaptación a situaciones cambiantes u obstaculiza la consecución de los objetivos de la organización (desplazamiento de metas), o cuando se desarrolla un espíritu de cuerpo entre los funcionarios que los lleva a defender sus propios intereses por encima de su clientela y de las órdenes de los altos funcionarios de elección, la burocracia muestra sus disfunciones típicas.

También desde un enfoque estructural funcionalista, Selznick (1948a, 1948b) centra su atención en mostrar que, si bien la presión burocrática, entendida como el apego a las reglas y a los procedimientos formales, tiene un papel de peso en el funcionamiento de la burocracia estatal, no se pueden descuidar los procesos informales de adaptación a las demandas de los grupos políticos o de presión ni las estrategias de búsqueda de apoyo político que tienen por objetivo garantizar su supervivencia. Una adecuada comprensión de la burocracia, indica, debe permitir interpretar tanto el sistema formal como sus desviaciones, esto es, su relación con los lazos informales de lealtad de clase, camarillas de poder o compromiso externo.

En un estudio considerado bisagra, Crozier (1963/1969) afirma que las disfunciones burocráticas descriptas por Merton y Selznick (ritualismo, rigidez, formación de un espíritu de casta) no son patologías, sino características inherentes al funcionamiento de los cuadros burocráticos estatales. La burocracia estatal constituye un espacio en el cual los actores individuales o grupales se encuentran vinculados

\footnotetext{
4 Bendix (1945/1960) ya afirmaba que la burocracia más que un medio de órganos políticos conforma un monopolio potencial de poder que puede sabotear las decisiones políticas y ejecutarlas según su propio criterio. La aclamada "neutralidad política de los funcionarios" en realidad significa —indica — que solo hacen concesiones a los grupos políticos lo bastante fuertes para imponerlas.
} 
no solo por reglas formales, sino también por relaciones de poder. En un ambiente caracterizado por la incertidumbre y el conflicto, la dinámica burocrática puede ser definida como un juego organizacional que enfrenta a actores que buscan controlar áreas de incertidumbre y aumentar al máximo su nivel de negociación. ${ }^{5}$ Como consecuencia, las decisiones del poder político no encuentran necesariamente en la burocracia una complaciente vocación de servicio. Sus agentes, por el contrario, son capaces de poner en juego, individualmente o en grupos, estrategias para negociar según sus propios intereses o metas. Sobre estas bases, algunos abordajes dan un paso más para registrar junto a las tensiones políticas internas, definidas como luchas individuales o grupales por imponer intereses o valores, la capacidad del cuadro administrativo para conformarse como un actor que interviene con peso propio en las luchas políticas.

\section{La burocracia como fuerza política}

Situando sus aportes en el campo de la teoría económica de la elección racional, Niskanen (1971) asegura que la burocracia y el gobierno representativo luchan entre sí por el presupuesto, recurso vital del funcionamiento estatal. Capaz de perseguir sus propios intereses o percepciones, la estructura burocrática actúa —indica- como "maximizadora de presupuesto". Su posición monopólica sobre la información de los costes de producción y sobre la agenda pública le permite, por ejemplo, forzar a los políticos electos a votar un presupuesto sobredimensionado. Preocupado, apuesta por mecanismos tales como el nombramiento de asesores políticos en cargos clave, que permitan controlar los excesos del poder administrativo y revitalizar la dirección política. ${ }^{6}$ Con argumentos diferentes, que se reconocen

\footnotetext{
5 En un trabajo posterior, propone junto a Friedberg un marco analítico llamado "sistema concreto de acción" que permite identificar las batallas de poder y las negociaciones estratégicas por medio de las cuales los actores burocráticos, dotados de márgenes de libertad y transformación, enfrentan las arenas de incertidumbre propias de toda burocracia (Crozier \& Friedberg, 1974).

6 No son pocos los estudios actuales, caso de Jackson (1982), que insisten en analizar los actores del sector público según su fin de maximizar su propio rédito y satisfacción.
} 
en los cauces del institucionalismo, Peters también reclama que la burocracia estatal sea analizada como un actor del proceso político cuya importancia no deja de crecer. La defensa de la artificial separación entre las instancias administrativas y los órganos políticos representativos solo puede conducir " [...] a someterlas efectivamente a otros tipos de influencias políticas, incluso más malignas, porque habiendo sido declaradas extintas resultan más difíciles de identificar y controlar por la ciudadanía" (Peters, 1978/1999, p. 299).

Tras reconocer, basándose en Crozier y otros, que en el funcionamiento interno de la burocracia estatal la jerarquía de autoridad piramidal y la cadena estricta de mando se encuentran amenazadas por el peso de la negociación y la formación de coaliciones, y la uniformidad y la previsibilidad por la formación de estratos que interpretan diferencialmente las normas, Peters (1978/1999) propone un análisis que distingue varias dimensiones de la actividad política de los administradores. Bajo el nombre de "supervivencia de las políticas", la primera dimensión considera las actividades formales e informales que realizan los burócratas para elaborar una política o bien para mantener y hacer crecer la organización. "No adoptamos — dice Peters_ la idea totalmente cínica de que las oficinas sólo se interesan por un aumento de su presupuesto, pero tampoco podemos adoptar la posición ingenua de que las oficinas sólo se preocupan por la realización de sus tareas constitucionales y legalmente designadas" (1978/1999, p. 114). La segunda dimensión analítica que plantea se refiere a las interacciones formales e informales de los administradores con otros funcionarios públicos (legisladores, miembros del ejecutivo, etc.) y con actores políticos no oficiales (sobre todo representantes de grupos de presión).

En lo tocante al conflicto que puede darse entre las demandas de los grupos de presión y la burocracia, Peters (1978/1999) considera que en la mayoría de las sociedades se ha evolucionado hacia una cooperación eficaz. Los administradores necesitan el apoyo político y la información que aportan los grupos de presión para fortalecerse frente a otras instituciones políticas, y los grupos de presión requieren 


\section{I GRACIELA INDA}

acceso al proceso de elaboración de las políticas estatales. En lo relativo al juego político con las legislaturas y el ejecutivo, la burocracia tiende a movilizarse por los fondos necesarios para sus operaciones basando su poder no solo en el monopolio relativo que tiene sobre la información y los conocimientos técnicos, sino también en su imparcialidad formal respecto de la política partidista y en su estabilidad a pesar de los vaivenes electorales. "Una de las armas principales del servicio civil en todo intento de ganar control sobre las políticas es su permanencia. Los políticos vienen y van; la burocracia permanece. Esto no sólo ofrece varias estrategias de largo plazo a los administradores que no están satisfechos con el 'amo' político actual, sino que también plantea a tales amos políticos algunos problemas muy difíciles de control de sus funcionarios públicos” (Peters, 1978/1999, p. 391).

Ante el interrogante de si la burocracia es capaz de aportar la dirección y el liderazgo requeridos por un gobierno, Peters (1993) responde que el gran volumen y la inercia de la burocracia, así como sus necesidades de apoyo político externo, hacen que privilegie inevitablemente no los problemas de gobernación, sino los relativos a su supervivencia organizacional. Además, no puede garantizar una dirección consensuada y coherente, porque lejos de constituir una institución unificada, con intereses comunes, es la combinación de diferentes enclaves muchas veces en pugna entre sí. Entre los recursos con que cuentan los líderes políticos para tratar de controlar el poder burocrático, ${ }^{7}$ señala el desarrollo de personal experto propio y de fuentes de información independientes, sean institucionalizas o mediante el uso de consultorías externas.

También indica que cuentan con el recurso de la legitimidad que proviene de ejercer la representación del pueblo y que lo pueden usar tanto para “[...] despertar la cólera del 'pueblo' en contra de los burócratas” (Peters, 1978/1999, p. 372) como para disponer de los poderes formales para controlarla. De este modo, la ausencia de

\footnotetext{
En un cambio notorio, años después, este autor reclama que las administraciones sean liberadas del excesivo control de los líderes políticos para que puedan funcionar mejor (Peters, 2004).
} 
una base electoral es tanto la fortaleza como la debilidad de la burocracia, pues lo que pierde en legitimidad lo gana en estabilidad e inmunidad (Peters, 1993). En suma, si bien no define el vínculo entre burocracia y política por la dominancia absoluta de uno de sus polos, Peters se inclina por subrayar las dificultades (de tiempo, de experticia, de costos, etc.) que enfrentan los dirigentes políticos para controlar efectivamente los crecientes poderes burocráticos.

Otro buen ejemplo de esta tendencia teórica que busca identificar no solo los conflictos internos, sino también la actuación política de la burocracia estatal, puede encontrarse en los desarrollos de Rudolph y Rudolph (1984). Partiendo de considerar, contra el supuesto weberiano, que rara vez hay plena identificación de los agentes burocráticos con los roles prescriptos, afirman estos autores que la burocracia estatal se caracteriza no tanto por relaciones consensuales, sino por el carácter endémico de las luchas por el poder que buscan imponer valores, intereses o fines. En la arena política externa - prosiguen- la burocracia no tiene un poder meramente instrumental y apartidista, sino que conforma un actor comprometido en la lucha por el poder, en alianza o conflicto con otros actores políticos. No se trata de un cuerpo sin voluntad ni intereses que recibe objetivos desde afuera, sino que es capaz de perseguir sus propios propósitos sustantivos. Weber se equivoca al pensar que solo los demagogos ponen en juego el personalismo, la irracionalidad y los sentimientos comunitarios: los burócratas bien pueden emprender formas de autoridad carismática y estrategias de lealtad en el ejercicio de sus funciones.

Vale agregar que no son pocos los trabajos que se inscriben en esta línea discursiva que emplaza a la burocracia como una potencial fuerza política a la vez que destaca sus tensiones internas. Más aún, Petit (1988) sostiene que la idea más aceptada en la literatura especializada es la que identifica dos dimensiones de la actividad política de los administradores: 1) la competencia y los conflictos de poder intraorganizacionales; y 2) la función de los administradores como fuerza política autointeresada que busca influir o mediar en la formulación y ejecución de las políticas públicas. 


\section{Burocracia, tecnocracia y dirigencia política en la clase dominante}

En los discursos teóricos que en los sesenta y setenta anuncian la emergencia de sociedades poscapitalistas o posindustriales, se plantea abiertamente la cuestión de la pertenencia de la burocracia (y en algunos autores, de una nueva capa, la tecnocracia) a la clase políticamente dominante. Partiendo de suponer que en las sociedades poscapitalistas se produce la disociación entre las posiciones de dominación económica y las de autoridad política, Dahrendorf (1962) sostiene que la clase políticamente dominante no está integrada por los propietarios de los medios de producción, como en las sociedades capitalistas del pasado, sino por los titulares de funciones burocráticas y los dirigentes políticos (ministros del ejecutivo, miembros del Parlamento, etc.). ${ }^{8}$ En esa coparticipación, señala a tono con Weber, la autoridad política que ejercen los burócratas "[...] es prestada, esto es, se trata de una autoridad delegada, que en última instancia se remite a ciertas funciones extra burocráticas a las que corresponde la más amplia facultad de ordenar. Aun cuando estas órdenes sean transferidas específicamente e incluso adaptadas y modificadas por la burocracia, tienen su origen fuera de la misma" (Dahrendorf, 1962, p. 315). A diferencia de otras estructuras, como las industriales, en las que rige una división dicotómica entre posiciones de dominación y de sumisión, entre quienes mandan y quienes obedecen, en el cuadro administrativo estatal de las sociedades posindustriales tiene lugar - según el autor - una graduación y una ampliación de las competencias y los ámbitos de autoridad que hace imposible la existencia de grupos enfrentados por la distribución del poder. En consecuencia, la clase políticamente dominante está formada desde su perspectiva no solo por altos cargos, sino por políticos y burócratas de todos los niveles que ejercen autoridad sobre otros agentes.

\footnotetext{
8 Esta hipótesis de la autonomía de los ámbitos económico y político que el autor aplica a la caracterización de las sociedades contemporáneas la retoma claramente de Weber. La diferencia es terminológica y radica en que emplea la expresión "clase políticamente dominante", cuando Weber reserva el término "clase" exclusivamente para referirse a la distribución del poder en la esfera económica.
} 
Touraine (1969/1973) también alude al pasaje de unas sociedades industriales, de explotación y acumulación, a unas sociedades posindustriales, de programación y alienación, definidas por la separación entre el conflicto industrial y el conflicto político, y por la primacía del poder de decisión sobre la propiedad económica. En las nuevas condiciones, la tecnocracia, integrada por una capa de la administración del Estado y por las grandes empresas estrechamente vinculadas a los ambientes de decisión política, se perfila, indica, como una nueva clase dominante en ascenso, poseedora de conocimiento e información y altamente meritocrática. Las clases dominadas de las sociedades posindustriales, en sintonía, no se definen por la carencia de propiedad, sino por la dependencia de las formas de organización propuestas por los grupos dirigentes. Los tecnócratas, miembros de un subgrupo que se distingue de los funcionarios subalternos y medios poco especializados, no son meros técnicos, sino verdaderos dirigentes políticos. "La tecnocracia es el poder ejercido en nombre del interés de los aparatos de producción y decisión, políticos y económicos, que aspiran al crecimiento y al poder y consideran la sociedad exclusivamente como el conjunto de los medios sociales que hay que utilizar para conseguir el crecimiento y el reforzamiento de los aparatos dirigentes que la controlan” (Touraine, 1969/1973, p. 72).

En su conceptualización de la sociedad posindustrial, Bell (1976) también enfatiza el carácter central del conocimiento en la toma de decisiones y la consecuente emergencia de una nueva clase dirigente que combina, no siempre sin rispideces, decisiones científicas y técnicas, fruto del cálculo instrumental, con decisiones políticas, de carácter ideológico. En un aporte considerado pionero de las perspectivas contemporáneas que la toman por objeto, ${ }^{9}$ Meynaud (1965/1968) entiende por tecnocracia una forma de ejercicio del poder en la cual los políticos y los burócratas tienden a ser desplazados por una nueva élite dotada de una mentalidad racionalista, cientificista y confiada en

\footnotetext{
9 La cuestión de la tecnocracia no designa un campo homogéneo, sino que es objeto de variadas y hasta contradictorias interpretaciones. Para una visión panorámica pueden verse, entre otros trabajos, el artículo de Centeno y Wolfson (1997) y la compilación de Ochoa Henríquez y Estévez (2006). Aquí retomamos algunas de sus referencias más relevantes.
} 


\section{6 / GRACIELA INDA}

la resolución técnica de los problemas. Mientras que el simple técnico o burócrata asesora, el tecnócrata, formado en instituciones de élite, influye de manera decisiva o interviene activamente en la toma de decisiones, predeterminando las opciones posibles o dictaminando los cursos de acción más eficientes. Para escapar al peligro latente de un autoritarismo tecnocrático que percibe los conflictos sociales como disfuncionales y enfatiza la productividad del sistema, es preciso, añade el autor en una mirada que está lejos de ser celebratoria, que la tecnocracia esté subordinada a los políticos electos y a la ciudadanía.

Esa tirantez entre, por un lado, una mentalidad tecnocrática, cientificista, elitista, orientada hacia el cálculo y portadora de una ideología que busca una política sin conflictos, y, por otro lado, una práctica de la política basada en una democracia deliberativa, que implica la responsabilidad política de los dirigentes frente a un electorado llamado a participar, conforma un problema que ha suscitado la atención de los estudiosos de la tecnocracia (Fischer, 1989; Rouban, 1998; Radaelli, 1999, entre otros). García Pelayo, otro referente de peso, asegura que en la era posindustrial, caracterizada por la erosión de las fronteras entre estructura tecnoeconómica y estructura estatal, la tecnocracia, compuesta tanto por agentes económicos como por miembros del poder estatal altamente especializados, conforma "una estructura de poder en la cual los técnicos condicionan o determinan la toma de decisiones, tendiendo así a sustituir al político (o sustituyéndolo definitivamente) en la definición de las policies y a los burócratas tradicionales en la operacionalización de las decisiones o en su participación en la decisión misma” (1974, p. 33).

En suma, si bien hay algunos enfoques que proponen que la dirección de la política estatal debe quedar enteramente en manos de una élite tecnoburocrática preservada de la inestabilidad política (por ejemplo, Huntington, 1965), son mayoría las posturas que a la hora de pensar la composición de la clase políticamente dominante en tiempos poscapitalistas colocan junto a la burocracia o la tecnocracia a los dirigentes o responsables políticos, en una posición más o menos subordinada. Más tarde, en los noventa, junto a las grandes reformas del Estado y en estrecha relación con el auge del credo neoliberal, se 
reinstala en el campo académico la noción de tecnocracia, en esta ocasión propiciando una tajante separación entre la dirigencia política tradicional y una élite tecnocrática poseedora de un saber calificado, considerado neutral y universalizable. Los tecnócratas, libres de todo compromiso político o ideológico, deben desplazar a los políticos, puesto que es posible y deseable una administración científica de los asuntos públicos; el lugar central dentro del Estado no corresponde a instituciones de la democracia política con su tendencia igualitaria, sino a las posiciones que poseen el conocimiento científico y técnico; todo conflicto político puede ser solucionado mediante criterios técnicos avalorativos; los principios del mercado (eficiencia, eficacia, productividad, progreso) son los más aptos para comandar la administración del Estado: tales son los principios propuestos por el ethos tecnocrático neoliberal (Estévez, 2006).

\section{Políticos y funcionarios como actores interdependientes}

Bajo la consigna de que las transformaciones introducidas por el Estado de bienestar dan lugar a burocracias que actúan en un entorno complejo, habitado por múltiples y heterogéneos actores, a partir de los setenta una línea de investigación viene a subrayar que no es posible identificar una clara línea divisoria entre poder político y administración ni tampoco sostener premisas teóricas generales sobre la supremacía de una de ellas. Tras considerar que a medida que aumenta la jerarquía se modifican el ámbito y la modalidad de la toma de decisiones, la propuesta consiste en pensar las formas variables que adopta el vínculo entre funcionarios de mayor jerarquía y altos cargos políticos. Apelando a técnicas cualitativas de análisis, principalmente entrevistas, los referentes de esta línea de investigación ponen el acento en la comprensión subjetiva que tienen los agentes. Construyen modelos de comportamiento o imágenes que representan el grado y el modo en que las actitudes de los altos funcionarios y los 
dirigentes contribuyen a la toma de decisiones políticas. ${ }^{10}$ Veamos algunos casos.

Putnam (1973) entiende que en las altas esferas el rol burocrático puede oscilar entre dos polos. El representado por el burócrata clásico que se conduce según criterios técnicos objetivos, se aparta de las instituciones políticas y percibe la actuación de los líderes políticos como una interferencia irracional que obstaculiza las decisiones basadas en el mérito y en la experticia. Y el ocupado por el burócrata político que privilegia la negociación por sobre el reglamento y considera legítima la influencia política en las decisiones administrativas. Si en el primer caso acecha el peligro de una burocracia alejada de la ciudadanía, en el segundo son las prebendas y los patronazgos los riesgos latentes. Recuperando esa distinción, Jamil (1998) razona que un momento importante del análisis del vínculo entre administración pública y control político consiste en preguntarse si los servidores públicos son activos o pasivos, esto es, si tienen iniciativa respecto de las propuestas políticas o si se comportan como asesores que esperan instrucciones.

Aberbach, Putnam y Rockman (1981) elaboran cuatro imágenes típico-ideales que muestran cómo se desarrollan las relaciones de rol entre los empleados públicos de mayor jerarquía y los políticos profesionales. La primera imagen, referida a una marcada bifurcación entre política y administración, no resulta adecuada para describir los roles contemporáneos de burócratas y políticos. La segunda imagen, que distingue entre la lógica administrativa orientada hacia los hechos concretos y la lógica política orientada hacia la promoción de intereses, tampoco es una concepción relevante entre los entrevistados. La tercera, que establece una distinción entre la energía política y el equilibrio burocrático, sí aparece como una imagen dominante, pues si bien ambos están comprometidos en la gestación de políticas, sus estilos son diferentes: en tanto representan el paralelogramo de fuerzas existentes, los burócratas jerárquicos ofrecen estabilidad al

\footnotetext{
10 Vale agregar que no faltan estudios sobre los niveles de autonomía y la influencia de los empleados de base o de primera línea en la elaboración de las políticas públicas.
} 
sistema político, mientras que los políticos, motivados por sus ideologías, proporcionan la necesaria energía. Años después, Aberbach y Rockman (1988) proponen una cuarta imagen, la del híbrido puro, en sintonía, como veremos enseguida, con ciertas propuestas de la nueva gestión pública. En concreto, hacen referencia a funcionarios con un pie en el mundo de la política y otro en el de la experiencia y capacidad técnica, a funcionarios que dejan de ser piezas de una maquinaria para convertirse en actores expertos interiorizados de un modo de hacer política.

Las fronteras entre política y administración, recalcan Aberbach, Putman y Rockman (1981), son variables en tanto expresan la tensión entre las tracciones por establecer una burocracia pública meritocrática que garantice imparcialidad y eficiencia técnica, y las presiones para aumentar la presencia de los cargos de confianza con el objetivo de consolidar un cuadro administrativo sensible al liderazgo político. Por caso, mientras que en las democracias europeas esas fronteras son, en general, más definidas, en la norteamericana son más borrosas, dada la importancia de los arreglos informales y las lealtades políticas en las nominaciones de cargos públicos. Si en el juego de presiones, aducen los autores, la burocracia tiende a desplazar a los políticos, aparece el riesgo de una crisis de legitimidad y si los políticos dominan por completo, puede producirse una crisis de efectividad y/o la propagación de prácticas patrimoniales. Retomando la sucesión de imágenes propuesta por Aberbach y Rockman, Thwaites Rey (2001) señala que la vieja dicotomía entre política y administración "[...] no se corresponde con las prácticas concretas, que muestran cómo la política en el sentido de expresar voluntades e intereses, no queda acotada al momento de la formulación de una política concreta, sino que impregna todo el proceso de ejecución” (2001, p. 3).

En continuidad con las investigaciones mencionadas, se tornan numerosos los estudios con base empírica, histórica y geográficamente demarcados, que se abocan a tratar la relación entre política y administración prestando atención al modo de ocupación de los cargos, al grado de filiación partidaria de los burócratas, a la percepción que tienen políticos y funcionarios respecto de sus respectivos 
roles, a los vínculos entre los puestos más altos de la burocracia y los titulares de cargos políticos, a las diferencias de comportamiento y actitudes entre las élites burocráticas y políticas, etc. A modo de ejemplo, podemos considerar la reciente investigación de Van der Wal (2013) que analiza con base en entrevistas las diferencias de motivaciones laborales entre las élites administrativas y las élites políticas en los Países Bajos, la Unión Europea y Estados Unidos. Contra las imágenes negativas de los políticos como maquiavélicos con ansia de poder y de los burócratas como conservadores interesados en la seguridad y el horario regular de oficina, destaca el altruismo y el deseo de trabajar para un bien mayor en ambos conjuntos. Pero también encuentra diferencias importantes, como, por ejemplo, que un grupo es motivado por estar en el centro de atención, mientras que el otro aprecia operar detrás de escena.

\section{Los burócratas como gerentes o gestores públicos}

Convertida en los noventa en un movimiento mundial por su alcance geográfico y su impronta en los más poderosos organismos internacionales, la perspectiva de la nueva gestión pública ${ }^{11}$ tiene como supuesto básico que las grandes burocracias centralizadas, producidas bajo los auspicios del estado de bienestar, con sus cadenas de mando verticales y sus culturas regidas por reglas son lentas, costosas e incapaces de adaptarse al mundo actual caracterizado por los cambios acelerados, las tecnologías de la información, la competencia global por la atracción de capitales y la presencia de demandas sociales cada

\footnotetext{
11 Según los especialistas, la nueva gestión pública no constituye una construcción conceptual perfectamente integrada y coherente, sino más bien un programa para la investigación y la puesta en marcha de reformas estatales en diversos países del mundo. Entre sus exponentes se desarrollan discusiones sobre la especificidad de la gestión pública frente a la privada, sobre si es posible aplicar el mismo modelo en todas las administraciones, sobre las formas de control gerencial, entre otras. Para un desarrollo de las corrientes teóricas que lo nutren y de sus tendencias internas pueden verse, entre muchos otros, los trabajos de López (2003), García Sánchez (2007) y Chica Vélez (2011). Aquí resaltamos los postulados comunes que definen el campo de la nueva gestión pública tal como son expresados por algunos de sus principales referentes y sintetizados en los estudios más aceptados sobre el tema (Pollitt, 1990; Hood, 1991; Aucoin, 1996).
} 
vez más exigentes. Su objetivo declarado apunta a transformar esas viejas estructuras y culturas burocráticas mediante su sustitución por organizaciones más pequeñas, flexibles y orientadas al cliente, con sistemas de gestión basados en incentivos y en la producción de resultados (Aberbach \& Rockman, 1999).

La eliminación de procedimientos y trámites que no tienen propósitos definidos, la creación de un diseño organizacional con un sentido de misión compartido y la evaluación de los funcionarios según resultados son algunas de las estrategias propuestas por los defensores de la "reinvención del gobierno" (Osborne \& Gaebler, 1994; Osborne \& Plastric, 1998) para superar el modelo tradicional weberiano. La competencia entre servicios públicos y privados, la división de la administración en sectores pequeños con presupuestos separados, los premios a los funcionarios según índices de eficacia son concebidos como mecanismos similares a los del mercado que pueden mejorar la eficiencia de la gestión burocrática.

Con el objetivo de alcanzar la eficiencia y la productividad de una empresa privada, cabeza de proa de las comúnmente llamadas reformas estatales de segunda generación, ${ }^{12}$ los impulsores de la nueva gestión pública incentivan el reemplazo de la expresión funcionario público por la de gerente público o gestor estatal para referirse a un profesional dotado de mayor responsabilidad que, más que recibir órdenes y acatar reglamentos, diseña estrategias y alcanza metas. La transformación del paradigma burocrático weberiano en una burocracia orientada al cliente exige que las prácticas administrativas no dependan exclusivamente de un superior jerárquico, no siempre en contacto directo con las demandas ciudadanas, sino que se encuentren guiadas por la obtención de resultados y la premisa de prestar mejores servicios al usuario (Barzelay, 1998).

\footnotetext{
12 La llamada segunda "generación" de reformas, impuestas por los organismos financieros internacionales, pone el énfasis en una serie de transformaciones "hacia adentro" del Estado, tales como la reestructuración organizativa, la profesionalización de la función pública, la desburocratización de normas o procedimientos y la introducción de nuevas tecnologías de gestión. A diferencia de la "primera generación de reformas" cuya meta central fue minimizar al aparato estatal, no mejorar sustantivamente su gestión (Oszlak, 1999).
} 
En cuanto a la dicotomía política/administración cabe decir que, si bien encontramos posiciones que abogan por una gestión administrativa neutral dirigida por criterios de rendimiento y eficacia e inmune a los vaivenes políticos (Overeem, 2005, 2006; Aguilar, 2010), son mayoría en este paradigma de la nueva gestión pública las posturas que apuntan a establecer una relación fluida y hasta una acción combinada entre gestores públicos y políticos. Allison (1983) y Gunn (1996) consideran que la nueva gestión pública trasciende tanto la concepción weberiana de la burocracia como la separación propuesta por Wilson. La gestión no es un ejercicio mecánico, sino una práctica compleja, con autonomía para decidir cursos de acción y resolver problemas, que inevitablemente se aproxima al mundo de la política. Los gestores públicos se encuentran guiados no solo por objetivos de eficiencia técnica, sino que también participan del proceso estratégico y político, cargado de intereses diversos y divergentes, mediante el cual se definen y ejecutan las políticas públicas. "Es una cuestión de preferencia personal el observar esta materia como gestión politizada o política gerencialista. La gestión pública y los políticos están inextricablemente relacionados en el proceso de gestionar cambios a nivel interorganizacional" (Metcalfe, 1996, p. 80).

Hughes (1996a) subraya que mientras en el modelo tradicional la relación entre líderes políticos y administradores se construye sobre una base técnica y despolitizada, de amo a sirviente, de quienes ordenan a quienes ejecutan, en el modelo de la nueva gestión pública la relación entre unos y otros asume distintos estilos de interacción y colaboración. Los buenos gestores públicos son capaces tanto de jugar en el campo de la política como de interactuar con agentes externos. Para este autor, el gerencialismo no implica una usurpación de la política por los tecnócratas, porque los políticos tienen la última palabra, pero sí implica que los administradores no pueden ser excluidos del proceso de elaboración de políticas. Magallón (2010) sostiene que más que recibir sus metas desde la dirigencia política, como propone la fórmula weberiana, los nuevos gestores públicos toman decisiones e impulsan proyectos, concilian y negocian con otras organizaciones públicas y con grupos de la sociedad civil; en suma, poseen capacidad 
administrativa, pero también aptitudes de liderazgo. ${ }^{13}$ Algunos autores (Bozeman, 1996; Hughes, 1996b) incluso reclaman que la burocracia gerencial gestione activamente sus relaciones externas, esto es, el trato con la prensa, el público, las organizaciones independientes y los grupos de presión. Oponiéndose a la fórmula weberiana que encarga a los políticos las relaciones externas y se preocupa únicamente por el interior de la organización, proponen que la gestión sea pensada como un área específica de intervención del proceso de elaboración de las políticas, junto a otras organizaciones y grupos de interés.

Es preciso mencionar que existe una abundante bibliografía abocada a criticar con firmeza el credo neoliberal en el campo de la administración, sus formas concretas de aplicación y sus resultados. La denuncia del intento de reemplazar la política democrática, vinculada con bases y objetivos sociales, con el debate de ideas y de programas colectivos, por un programa que se presenta como eminentemente técnico cuando en realidad es impuesto por organismos internacionales controlados por los gobiernos de los países centrales ocupa un lugar destacado en esta literatura.

Antes de las conclusiones, unos párrafos aparte merecen los esfuerzos analíticos, como el encarado por Oszlak (2006), por apropiarse críticamente de elementos de las corrientes teóricas que recorrimos para reexaminar la vieja dicotomía política-administración con el foco puesto en los países de América Latina. En concreto, este referente propone mirar la burocracia no como una institución con funciones predestinadas, sino como una organización compleja que se encuentra determinada por la naturaleza y el contenido de las políticas públicas que implementa. Una burocracia, subraya, es lo que hace y, por tanto, debe estudiarse en cada momento histórico y en cada contexto según su involucramiento en la política y en la implementación de políticas públicas. Y esto sin descuidar su poder

13 En una intervención reciente, Crozier (2000) señala que el poder del tecnócrata es más un poder político que un poder de experto, pues su éxito depende más de sus cualidades políticas que de la posesión de una ciencia. 
relativo con respecto a otros actores y su desempeño o productividad en el logro de los objetivos políticos.

Partiendo de considerar que existe una relación causal entre la naturaleza del régimen político y las diversas formas de dinámica burocrática, pretende desarrollar (con cuidado de no hacer extrapolaciones indebidas) tipologías de estilos de gestión de las burocracias. Algunos ejemplos. El personal diplomático tiende a comportarse como un estrato cerrado con jerarquías claramente definidas independientemente del régimen en el poder. La amplia difusión de modelos de gestión pública por las organizaciones financieras internacionales produce una creciente homogeneización de burocracias con historias diferentes. En países con inestabilidad política y frecuentes cambios en la naturaleza de los regímenes políticos, los 'retrasos' en el proceso de readaptación se vuelven crónicos. Hay que entender las diferencias entre las democracias establecidas en América Latina, por ejemplo, y las europeas o asiáticas. En fin, "las diferencias son múltiples: el grado de consolidación de un sistema de partidos, la influencia remanente de los militares, la relativa hegemonía del ejecutivo frente a otros poderes y actores políticos; la difusión del prebendalismo, el poder político de fuerzas militares irregulares (narcos o guerrillas), el peso político de los sindicatos de empleados públicos, entre otros" (Oszlak, 2006, p. 49). En esta línea, desde hace algunos años y como parte de un grupo de especialistas regionales cada vez más nutrido que asesora a diferentes gobiernos de la región en la implementación de programas de 'gobierno abierto', este autor coloca en primer plano las cuestiones de la transparencia, la participación y la colaboración dentro del Estado y entre este y la ciudadanía (Hofmann, Ramírez Alujas \& Bojórquez Pereznieto, 2013; Oszlak, 2014, entre otros).

\section{Conclusiones}

La fórmula weberiana, punto de arranque de nuestro recorrido, reconoce no una oposición, como a veces se dice ligeramente, sino una tensión en el seno del Estado moderno entre el cuadro administrativo legal racional, con su monopolio del saber, y los liderazgos políticos 
surgidos de la arenas partidarias y parlamentarias, dotados de cualidades carismáticas y capaces de conducir a las masas. Entendida como lucha por la conservación, reparto o traspaso del poder político, a la política, siempre en riesgo de ser invadida, le corresponde salvarse a sí misma suministrando la energía necesaria para dirigir, controlar y dotar de objetivos al aparato burocrático, inigualable en precisión y eficacia. Antes que una conformidad incondicional, este binomio weberiano suscita en el campo académico, como vimos, disímiles itinerarios teóricos, los cuales aportan definiciones y discusiones propias sobre el vínculo entre burocracia estatal y política.

a) El retrato del cuadro administrativo estatal como un cuerpo que puede dar lugar a un desplazamiento de metas, dotado de un espíritu propio, perforado por la informalidad, receptivo a influencias externas y atravesado por negociaciones y conflictos de poder interpersonales, coloca en primer plano la cuestión de cómo las lógicas internas y la necesidad de sobrevivir pueden funcionar como resistencias a los mandatos del poder político, cuya primacía no se discute. La política es aquí una actividad de actores individuales o grupales orientada a imponer sus intereses o valores en el interior del aparato administrativo, eventualmente afectados por actores económicos o políticos externos.

b) Ya sea que se inclinen por la dominancia de la burocracia o por la primacía de los dirigentes políticos, o bien por una relación variable entre ambos polos, las definiciones de la burocracia como una fuerza política que busca imponer sus propios intereses en el campo estatal, ya sean presupuestarios o de influencia en la definición de políticas, se alejan decididamente de la convicción weberiana que exige de los funcionarios una disciplina de obediencia puesta al servicio del poder político. La política de la burocracia es aquí una actividad bifronte que se expresa tanto en la competencia interna que trastoca la jerarquía y la formalidad del cuerpo burocrático, como en el juego de conflicto, alianza y compromiso, que entabla en pie de igualdad con otros actores estatales y grupos de presión.

c) Entre las teorías que advierten sobre la llegada de una era poscapitalista, la de Dahrendorf tiene la particularidad de poner el 
acento en la multiplicación de los ámbitos de ejercicio de autoridad en el Estado para aludir a un proceso de ampliación de la clase políticamente dominante. Integrada por todas las posiciones burocráticas y políticas que ejercen algún grado o forma de mando, bajo la primacía de las segundas, la nueva clase dominante dibujada por este autor queda lejos de conformar una minoría al estilo weberiano. En contraste, la perspectiva que prevalece se muestra preocupada por la delimitación de la tecnocracia como tercera en discordia, esto es, como una minoría que afianza su poder en el ejercicio de una función cognitiva altamente especializada que eclipsa tanto las competencias del cuerpo administrativo como las capacidades de los órganos políticos. El creciente dominio de esa élite tecnocrática, que incorpora a representantes de los poderes económicos, es visto por algunos como una amenaza para la política democrática, a tono con Weber, mientras que para otros, enrolados en la prédica neoliberal, designa una forma de ejercicio del poder estatal que permite superar los conflictos políticos priorizando una racionalidad pretendidamente cientificista.

d) Las investigaciones que fijan su atención en los funcionarios y cargos políticos de alta jerarquía en diversos países y períodos ofrecen un catálogo destinado a ilustrar los diversos modos que puede adoptar la relación entre administración y política desde la óptica de los propios actores. Las figuras del burócrata clásico, del burócrata político, del híbrido, entre otras, les permiten pronunciarse a favor de un vínculo que se desenvuelve según la coyuntura institucional. A contramano de la distinción que realiza Weber entre el funcionariado público, disciplinado y obediente, y el dirigente político, apasionado y luchador, sostienen así la existencia de fronteras inconstantes y difusas que se resisten a una conceptualización con pretensión de generalidad. Eso sí, a la hora de pensar los peligros potenciales que entrañan los diferentes modos de vinculación, el temor por un abuso burocrático que paralice la iniciativa política no deja de estar presente.

e) Versus el prototipo weberiano del cuadro burocrático que recibe órdenes en medio de una estructura vertical con competencias rigurosas, los discursos de la nueva gestión pública promueven la 
figura del gestor estratégico dotado de iniciativa, de un sentido de misión y de un amplio margen de autonomía respecto de los políticos electos. La arenga gerencial por un funcionario entusiasmado por la gestión de las políticas y comprometido con ellas, señalan con nostalgia Olsen (2005) y Du Gay (2012), atenta contra la imparcialidad y la responsabilidad de mostrar los posibles inconvenientes de una política propias del ethos burocrático weberiano. Si en esta geografía de raigambre neoliberal hay versiones que apuntalan la idea de una neutralidad política de los gestores públicos, concita más consenso la postura que aboga por una relación colaborativa entre dirigentes políticos electos y gestores dotados de capacidades técnicas, pero también de talento para la negociación y el liderazgo. No es extraña esta predominancia, pues la política queda aquí equiparada a una actividad de gestión orientada al cumplimiento óptimo de objetivos institucionales con el menor coste posible.

Una última reflexión. Si en la matriz weberiana las masas son encauzadas en una participación que contiene sus desbordes irracionales, quedando los líderes de la burguesía a cargo de la acción política, la cual implica necesariamente dotes demagógicas, en los itinerarios teóricos que le siguen la cuestión del impacto de las luchas populares en la división del trabajo estatal es más imperceptible y en algunos casos hasta desaparece. Aunque hay registros de la incidencia y hasta de la presencia directa de los poderes económicos o grupos de presión en el campo burocrático estatal, las mayorías populares y sus formas de organización política son solo consideradas de forma elíptica y limitada, ${ }^{14}$ habitualmente como base electoral atomizada que dota de representatividad a la dirigencia política del aparato estatal. La estampa del ciudadano cliente, desvinculado de todo conflicto social, portador de demandas puntuales, tal como la proponen los defensores de la nueva gestión pública, representa sin duda el punto culminante del

\footnotetext{
14 Cuando aparece la mención a las clases dominadas, casos de Dahrendorf y Touraine en nuestro recorrido, es para hacer referencia a los grupos momentáneamente sometidos a los mandatos del grupo dirigente, esto es, con la posibilidad siempre abierta de pasar a ejercer posiciones de autoridad o bien influir en la toma de decisiones y pasar a formar parte de una clase dominante cada día más amplia.
} 
desplazamiento que mencionamos. Finalmente, la máxima weberiana ${ }^{15}$ de un ejercicio del poder estatal que mantiene una relación contingente y exterior con los conflictos de clase que caracterizan el orden económico preserva su vigencia en las trayectorias analizadas. En ellas, en efecto, la práctica estatal no se vincula orgánicamente con el poder de una clase o de una alianza de clases, a la usanza marxista. Por el contrario, los poderes de clase asoman como influjos de ciertos grupos de presión, como limitaciones al accionar estatal, como variables contextuales, etc., pero de ningún modo como inscriptos en la naturaleza misma del aparato burocrático y la actividad política.

\section{Referencias}

Abellán, J. (2004). Poder y política en Max Weber. Madrid: Biblioteca Nueva. Aberbach, J. D., Putman, R. D., \& Rockman, B. A. (1981). Bureaucrats \& politicians in Western democracies. Estados Unidos: Harvard University Press. Aberbach, J. D., \& Rockman, B. A. (1988). Revisión de la imagen IV: los roles ejecutivos y políticos. El Gobierno: Publicación Internacional sobre Politicas y Administración, 1(1), 1-25.

Aberbach, J. D., \& Rockman, B. A. (1999). Reinventar el gobierno: problemas y perspectivas. GAPP, 15, 3-17.

Aguilar, L. (2010). El futuro de la gestión pública y la gobernanza después de la crisis. Frontera Norte, 22(43), 187-213.

Allison, G. (1983). Public and private management: are they fundamentally alike in aii unimportant respects? In J. Perry \& K. Kraemer (Eds.), Public management:public and private perspectives (pp. 395-411). California: Mayfield Publishing.

Anter, A. (2010). L'histoire de l'État comme histoire de la bureaucratie. Trivium. Revue franco-allemande de sciences humaines et sociales, 7, 1-18.

Aucoin, P. (1996). Reforma administrativa en la gestión pública: paradigmas, principios, paradojas y péndulos. En Q. Brugué \& J. Subirats (selección de textos), Lecturas de gestión pública (pp. 491-515). Madrid: Instituto Nacional de Administración Pública.

\footnotetext{
15 Para un análisis detallado de esta cuestión, esencial en el debate que mantiene Weber con la teoría marxista, puede verse (Inda, 2009).
} 
Barzelay, M. (1998). Atravesando la burocracia: una perspectiva de la administración pública. México: Fondo de Cultura Económica.

Bellido, F. (2017). La burocratización del poder político: notas sobre sus consecuencias en las democracias parlamentarias. Astrolabio. Revista Internacional de Filosofía, 20, 1-7.

Beetham, D. (1967). Bureaucracy. Mineapolis: The University of Minnesota Press.

Bell, D. (1976). El advenimiento de la sociedad post-industrial. Un intento de prognosis social. Madrid: Alianza Editorial.

Bendix, R. (1945/1960). Bureaucracy and the problem of power. In R. Merton et al., Reader in bureaucracy (pp. 114-135). Cambridge: Press.

Breuer, S. (1996). Burocracia y carisma: la sociología politica de Max Weber. Valencia: Edicions Alfons El Magnànim.

Bozeman, B. (1996). Los fundamentos de la gestión pública estratégica. En Q. Brugué \& J. Subirats (selección de textos), Lecturas de gestión pública (pp. 377-402). Madrid: Instituto Nacional de Administración Pública. Brown, M., \& Erie, S. (1984). Poder y administración: paradigmas alternativos para el análisis de la autonomía burocrática. En O. Oszlak (Comp.), Teoría de la burocracia estatal (pp. 162-196). Buenos Aires: Paidós.

Centeno, M., \& Wolfson, L. (1997). Redefiniendo la tecnocracia. Desarrollo Económico, 37(146), 215-240.

Chazel, F. (2000). Éléments pour une reconsidération de la conception weberienne de la bureaucratie. En F. Chazel, Aux fondements de la sociologie (pp. 183-204). Paris: Presses Universitaires de France.

Crozier, M. (1963/1969). El fenómeno burocrático. Buenos Aires: Amorrortu Editores.

Crozier, M. (2000). À quoi sert la sociologie des organisations? Paris: Éditions du Seuil.

Crozier, M., \& Friedberg, E. (1974). The actor and the system. Chicago: Chicago University Press.

De Sheinbaum, B. (1980). Dos dilemas de la burocracia política capitalista. Revista Mexicana de Sociología, 42(3), 969-990.

Chica Vélez, S. (2011). Una mirada a los nuevos enfoques de la gestión pública. Administración \& Desarrollo, 39(53), 57-74.

Dahrendorf, R. (1962). Las clases sociales y su conflicto en la sociedad industrial. Madrid: Ediciones Rialp.

Du Gay, P. (2012). Elogio de la burocracia. Madrid: Siglo XXI. 
Estévez, A. (2006). Una genealogía de la tecnocracia. En H. Ochoa Henríquez \& A. Estévez (Comp.), Elpoder de los expertos: para comprender la tecnocracia (pp. 65-96). Maracaibo: Universidad del Zulia.

Fischer, F. (1989). Technocracy and the politics of expertise. Thousand Oaks: SAGE. García Pelayo, M. (1974). Burocracia y tecnocracia. Madrid: Alianza Universidad. García Sánchez, I. (2007). La nueva gestión pública: evolución y tendencias. Presupuesto y Gasto Público, 47, 37-64.

Gunn, L. (1996). Perspectivas en gestión pública. En Q. Brugué \& J. Subirats (selección de textos), Lecturas de gestión pública (pp. 41-55). Madrid: Instituto Nacional de Administración Pública.

Hofmann, A., Ramírez Alujas, J., \& Bojórquez Pereznieto, A. (Coord.). (2013). La promesa del gobierno abierto. México: Itaip.

Hood, C. (1991). A public management for all seasons? Public Administration, 69, 3-19.

Hughes, O. (1996a). La nueva gestión pública. En Q. Brugué \& J. Subirats (selección de textos), Lecturas de gestión pública (pp. 104-132). Madrid: Instituto Nacional de Administración Pública.

Hughes, O. (1996b). La gestión de las relaciones externas. En Q. Brugué \& J. Subirats (selección de textos), Lecturas de gestión pública (pp. 355-376). Madrid: Instituto Nacional de Administración Pública.

Huntington, S. (1965). Political development and political decay. World Politics, 17(3), 386-430.

Ihalainen, P., \& Palonen, K. (2018). Parliament as a conceptual nexus. In P. Ihalainen \& K. Palonen (Eds.), Parliament and parliamentarism: a comparative bistory of a European concept (pp. 1-16). New York: Berghahn Books.

Inda, G. (2009). Las concepciones del Estado de Durkheim y Weber ante la teoría marxista: vínculos, cruces y desacuerdos. Athenea digital: revista de pensamiento e investigación social, 15, 97-118.

Inda, G. (2012). Los dilemas del Estado moderno según Max Weber: un recorrido por sus Escritos politicos (1917-1920). Revista Estudios Avanzados, 7, 13-38.

Jackson, P. (1982). Managing people at work. London: McGraw-Hill.

Jamil, I. (1998). La cultura administrativa: una forma de comprender la administración pública en distintas culturas. Gestión y Política Pública, VII(1), 61-82. 
López, A. (2003). La nueva gestión pública: algunas precisiones para su abordaje conceptual. En Serie I: Desarrollo institucional y reforma del Estado. Documento No 68 (pp. 1-28). Buenos Aires: INAP.

Machiavelli, F., \& Proulx, D. (2006). Tecnocracia y decisión política. En H.

Ochoa Henríquez \& A. Estévez, Elpoder de los expertos: para comprender la tecnocracia (pp. 191-216). Maracaibo: Universidad del Zulia.

Magallón, A. (2010). ¿De burócratas a gerentes públicos? El yo ideal organizacional. Multidisplina, 7, 73-83.

Merton, R. (1949/1965). Teoría y estructura sociales. México: Fondo de Cultura Económica.

Metcalfe, L. (1996). Gestión pública: de la imitación a la innovación. En Q. Brugué \& J. Subirats (selección de textos), Lecturas de gestión pública (pp. 79-100). Madrid: Instituto Nacional de Administración Pública. Meynaud, J. (1965/1968). La tecnocracia: ¿mito o realidad? Madrid: Tecnos.

Mommsen, W. (1981). Max Weber: sociedad, politica e historia. Buenos Aires: Alfa.

Niskanen, W. (1971). Bureaucracy and representative government. Chicago: Aldine Publishing Co.

Olsen, J. (2005). Quizás sea el momento de redescubrir la burocracia. Revista CLAD Reforma y Democracia, 31, 1-24.

Overeem, P. (2005). The value of the dichotomy: politics, administration, and the polítical neutrality of administrators. Administrative Theory \& Praxis, 25(2), 311-329.

Overeem, P. (2006). In defense of the dichotomy: a response to James H. Svara. Administrative Theory \& Praxis, 28(1), 140-147.

Osborne, D., \& Gaebler, T. (1994). La reinvención del gobierno. La infuencia del espiritu empresarial. Barcelona: Paidós Ibérica.

Osborne, D., \& Plastric, P. (1998). La reducción de la burocracia: cinco estrategias para reinventar el gobierno. Buenos Aires: Paidós.

Oszlak, O. (1980). Políticas públicas y regímenes políticos: reflexiones a partir de algunas experiencias latinoamericanas. Estudios CEDES, 3(2), 1-43.

Oszlak, O. (1999). Quemar las naves (o cómo lograr reformas estatales irreversibles). Aportes para el Estado y la Administración Gubernamental, 6(14), 1-24.

Oszlak, O. (2006). Burocracia estatal: política y políticas públicas. POSTData, 11, 11-56. 
Oszlak, O. (2014). Gobierno abierto: hacia un nuevo paradigma de gestión pública. En E. Kaufman \& O. Oszlak, Teoría y práctica del gobierno abierto: lecciones de la experiencia internacional (pp. 5-56). Buenos Aires: OEA-Red Gealc-IDRC.

Palonen, K., \& Rosales, J. (Eds.). (2015). Parliamentarism and democratic theory. Historical and contemporary perspectives. Opladen-Berlin-Toronto: Barbara Budrich Publishers.

Peters, G. (1978/1999). La politica de la burocracia. México: Fondo de Cultura Económica.

Peters, G. (1993). Política pública y burocracia. Foro Internacional, 33(131), 54-87.

Peters, G. (2004). Cambios en la naturaleza de la administración pública: de las preguntas sencillas a las respuestas difíciles. En M. Pardo (Comp.), De la administración pública a la gobernanza (pp. 69-95). México: Colmex.

Petit, G. (1988). Política y burocracia. Revista Mexicana de Sociología, 50(2), 179-220.

Pollitt, C. (1990). Managerialism and the public services. The Anglo-American experience. Oxford: Blackwell.

Putnam, R. (1973). The political attitudes of sénior civil servants in Western Europe: a preliminary repon. British Journal of Political Science, 3, 257-290.

Radaelli, C. (1999). The public policy of the European Union: whither politics of expertise? Journal of European Public Policy, 6, 757-774.

Román Masedo, L. (1997). Política y administración. Algunas notas sobre el origen y la evolución del debate teórico. Revista de Estudios Políticos (Nueva Época), 98, 115-135.

Rouban, L. (1998). La fin des technocrates? Paris: Presses de Sciences Po.

Rudolph, L., \& Rudolph, S. (1984). Autoridad y poder en la administración burocrática y patrimonial. En O. Oszlak (Comp.), Teoría de la burocracia estatal (pp. 121-161). Buenos Aires: Paidós.

Selznick, P. (1948a). An approach to a theory of organization. American Sociological Review, 8, 47-54.

Selznick, P. (1948b). Foundations of the theory of organization. American Sociological Review, 13(1), 25-35.

Smith, B. (1988). Bureaucracy and political power. New York: St. Martin's.

Thwaites Rey, M. (2001). Tecnócratas vs. punteros. Nueva falacia de una vieja dicotomía: política vs. administración. Encrucijadas, 6, 1-15.

Touraine, A. (1969/1973). La sociedad post-industrial. Barcelona: Ariel. 
Van der Wal, Z. (2013). Mandarins vs. machiavellians? On differences between work motivations of political and administrative elites. Public Administration Review, 73(5), 749-759.

Weber, M. (1918/2003). Parlamento y gobierno en una Alemania reorganizada. Una crítica política de la burocracia y de los partidos. En M. Weber, Obras selectas (pp. 255-400). Buenos Aires: Distal.

Weber, M. (1919/1983). La política como profesión. En M. Weber, El trabajo intelectual como profesión (pp. 61-156). España: Bruguera.

Weber, M. (1919/1984). La futura forma institucional de Alemania. En M. Weber, Escritos politicos II (pp. 253-293). México: Folios Ediciones. Weber, M. (1921/1972). El carácter nacional y los Junkers. En M. Weber, Ensayos de sociología (pp. 471-482). Barcelona: Ediciones Martínez Roca.

Weber, M. (1922/1969). Economía y sociedad. Esbozo de sociología comprensiva. México: Fondo de Cultura Económica.

Wilson, W. (1887). The study of administration. Political Science Ouarteriv, 209-210.

Zabludowski, G. (2000). Burocracia. En L. Baca, J. Olamendi, F. BoskerLiwerant, I. Castañeda, G. Cisneros, \& G. Pérez Fernández, (Comp.), Léxico de la política (pp. 12-18). México: Fondo de Cultura Económica. 